\title{
Diverticulitis perforada causante de fascitis necrotizante de miembro inferior
}

Perforated diverticulitis causing necrotizing fasciitis of the lower limb

Diverticulite perfurada causando fasceíte necrosante do membro inferior

María del Mar Aguiriano Casanova ${ }^{1}$

ORCID 0000-0001-7921-9002

aguirianomar@gva.es

Úrsula Ponce Villar ${ }^{2}$

DOI $10.31837 /$ cir.urug/6.1.5

ORCID 0000-0002-4458-922X

ursulapv85@hotmail.com

Fabián Peiró Monzó ${ }^{3}$

ORCID 0000-0002-4380-1479

fabianpeiro@hotmail.com

Carmen Montesinos ${ }^{4}$

ORCID 0000-0002-6047-4289

montesinos_carmel@gva.es

Jesús Seguî

ORCID 0000-0001-5456-0538

segui jes@gva.es

Recibido: 26 de abril de 2021 Aceptado: 25 de noviembre de 2021

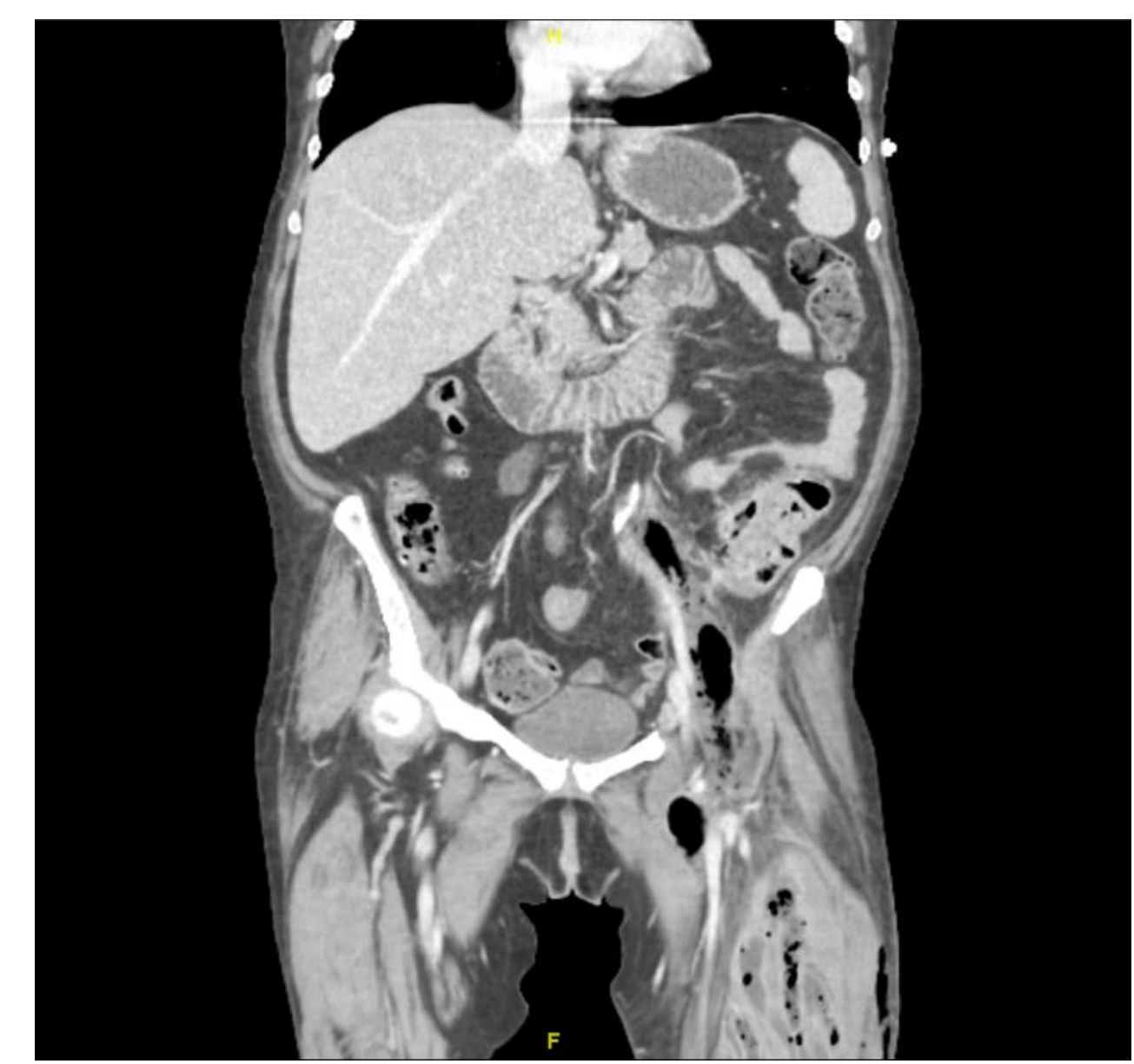

Fig. 1 Diagnóstico: Diverticulitis perforada causante de fascitis necrotizante.

\footnotetext{
${ }^{1}$ Residente Primer año de Cirugía General y Aparato Digestivo. Hospital Francesc de Borja, Gandía, Valencia, España

${ }^{2,3}$ Facultativo Especialista Adjunto de Cirugía General y Aparato Digestivo. Hospital Francesc de Borja, Gandía, Valencia, España

${ }^{4}$ Facultativo Especialista Adjunto y Jefa Clínica de Cirugía General y Aparato Digestivo. Hospital Francesc de Borja, Gandía, Valencia, España

${ }^{5}$ Facultativo Especialista Adjunto y Jefe de Servicio de Cirugía General y Aparato Digestivo. Hospital Francesc de Borja, Gandía, Valencia, España
} 


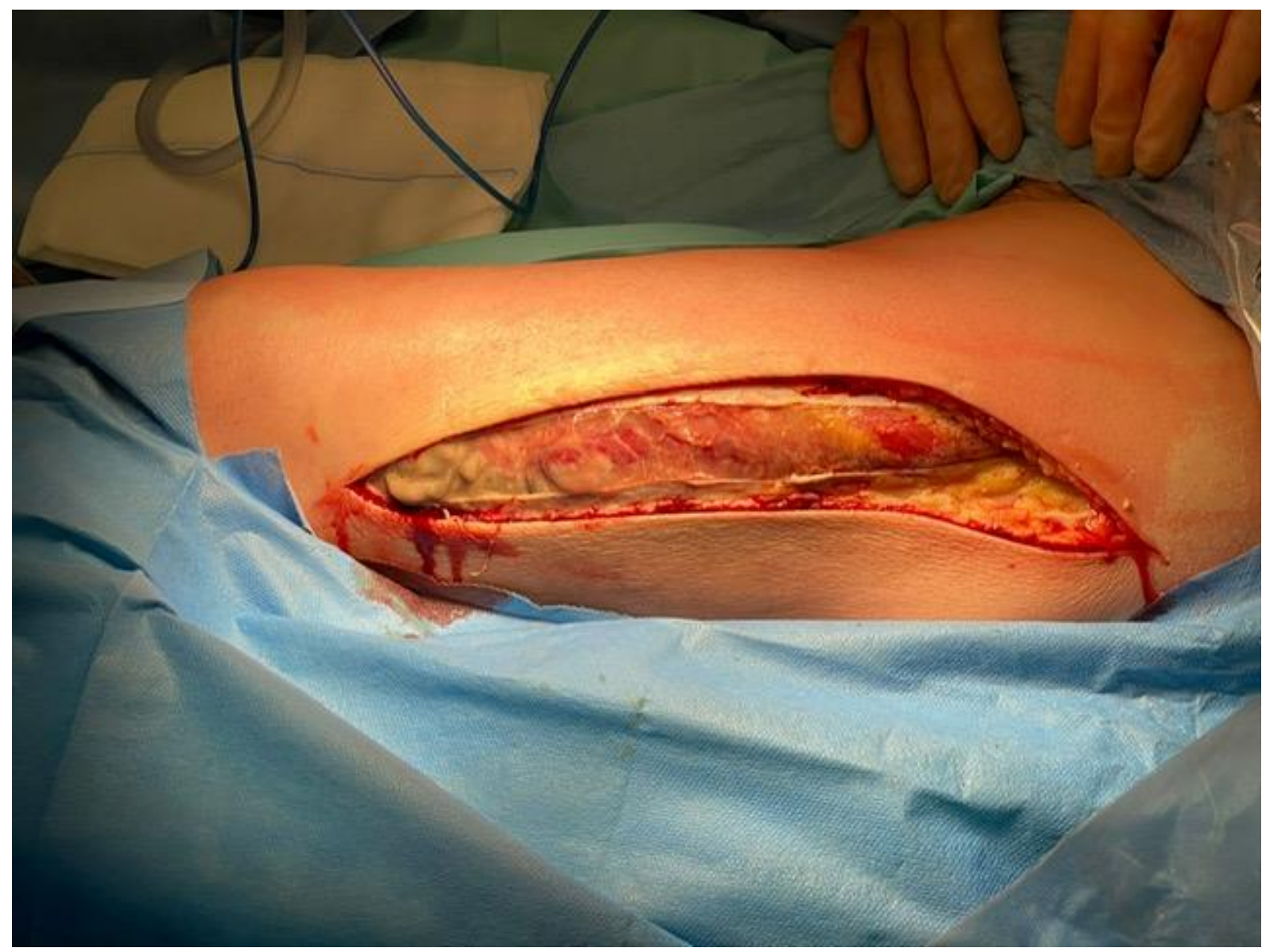

Fig. 2 Desbridamiento quirúrgico realizado

Mujer de 59 años, con antecedentes de diverticulosis de colon, que acude por dolor en la región inguinal y en el miembro inferior izquierdo de dos meses de evolución.

En una primera instancia, la paciente se presentó con clínica de sepsis y se objetivó un eritema en el miembro inferior izquierdo, asociado a celulitis y crepitación subcutánea.

La TC mostraba una colección hidroaérea en psoas y retroperitoneal que asciende hasta la cavidad abdominal hallándose una diverticulitis perforada. El tratamiento quirúrgico se basó en el drenaje de la colección retroperitoneal y sigmoidectomía, seguido de una fasciotomía, desbridamiento y lavado del muslo.

La perforación de un divertículo puede formar un absceso intraperitoneal desarrollando una peritonitis o un absceso retroperitoneal, derivando en una translocación bacteriana hacia la extremidad inferior, debido a la comunicación existente en el anillo crural, generando una fascitis necrotizante del miembro. 